\title{
Principle of Initiation of Impulse Applied to Phenomena of Conduction
}

\author{
By \\ Kazumi Yamagiwa \\ (山 極 一三) \\ From the Department of Physiology, Tokyo Medical and Dental \\ University, Yushima, Bunkyo-ku, Tokyo
}

(Received for publication, September 6, 1958)

The relation between an active length $\mathrm{x}$ and the resting length $\mathrm{y}$ to be excited by $\mathbf{x}$ is expressed by the following equation ${ }^{1,2)}$ :

$$
\mathrm{y}=\mathrm{k} \ln f\left(1-\mathrm{e}^{-\mathrm{x} / \mathrm{k}^{\prime}}\right)
$$

$k, k^{\prime}$, length constants of resting and active membranes respectively; $f$ (safety factor of excitation) $=\frac{\mathrm{V}}{\mathrm{S}}=\frac{\mathrm{V}}{\mathrm{r}_{\mathrm{m}} \mathrm{i}_{\mathrm{s}}} ; \mathrm{V}$, action potential ; $\mathrm{S}$, threshold voltage $; r_{m}, i_{s}$, membrane resistance and threshold current, respectively, for unit length of fibre.

Now, for initiation of impulse, two conditions are required to be satisfied $^{11}$ : and

1) Type I of $y$-x-curve (Fig. 1), crossing the $45^{\circ}$ line at $\mathrm{x}=\mathrm{L}$ and $\mathrm{M}$,

2) Simultaneous excitation of " $L$ " (Fig. 1), that is, $\Delta t=t_{L}-t_{O} \leqq D$ $\left(t_{0, L}\right.$, response times at points $x=0$ and $x=L ; D$, duration of activity at point $\mathrm{x}=0$ ). Of these two, which together we call here the principle of initiation of impulse, the former is well established in normal fibres ${ }^{3}$, so usually the latter is the only requirement. This principle was shown to be very useful for explaining a number of facts concerning electric excitation $^{4-6)}$. The present paper describes how well the principle or the original eq. (1) operates in various phenomena of conduction, in more details or more exactly than before" ${ }^{1}$.

\section{Transmission as the Basis of Conduction}

The propagation in unmyelinated fibres is certainly continuous. In view of the present principle, however, an active length larger than $L$ exciting another length larger than $\mathrm{L}$ (that is, a discontinuous transmission from length to length) must exist throughout as the basis of continuous conduction. ${ }^{11}$ A functional significance of the so-called action length, at 


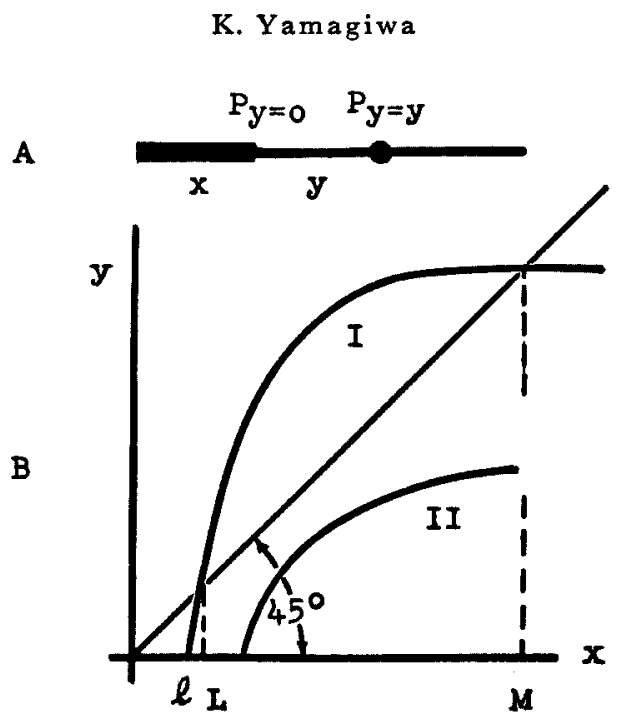

Fig. 1. y-x-relation, schematic. $x$, active length; $y$, resting length to be excited by $\mathrm{x} ; \mathrm{P}_{\mathrm{y}-0}, \mathrm{P}_{\mathrm{y}-\mathrm{y}}$, potentials at $\mathrm{y}=0$ and $\mathrm{y}=\mathrm{y}$ respectively; $l \fallingdotseq$ $0.1, \mathrm{~L} \fallingdotseq 0.11$ and $\mathrm{M} \fallingdotseq 11 \mathrm{~mm}$ in case $\mathbf{k}=5 \mathrm{~mm}, \mathbf{k}^{\prime}=1 \mathrm{~mm}$ and $f=10.1$ )

least of a portion near the front, is appreciated from this view-point. ] is interesting to note that in Lillie's nerve model in particular conditior (for example, electrotonus) where the activation wave proceeds decri mentally, the wave fails to conduct when the wave length gets down to certain small value.")

In myelinated fibres, the so-called action length has almost nothin of this function, because the action current as stimulus is scarcely strengtl ened by multi-nodal activity ${ }^{8), 91}$. But, what is important here is the actio length in the nodal membrane itself, where, too, a certain "L" exis highly probably (see App. 1, note 1). Whether the excitation produc a spike or not, depends upon whether $\mathrm{L}$ is wholely or partly excitec Details will be stated later.

II. Safety or Initiation of Propagation of Impulse

1) Judgement from $y$ - $x$-relation

The mathematical condition for establishment of type I of $\mathrm{y}$-x-rel: tion is $f \geqq \frac{1}{\mathrm{~K}}(1+\mathbf{K})^{(1+K) / K}\left(\mathbf{K}=\mathbf{k} / \mathbf{k}^{\prime}\right)^{3)}$; hence, the establishment is th safer, the larger $f$ and $\mathrm{K}$ or the larger $\frac{\mathrm{V}}{\mathrm{S}}$ and $\frac{\mathrm{r}_{\mathrm{m}}}{\mathrm{r}_{\mathrm{m}}^{\prime}}$ are, if assumed $\mathrm{k}=$ $\sqrt{\frac{r_{m}}{r_{i}}}$ and $k^{\prime}=\sqrt{\frac{r_{m}^{\prime}}{r_{i}}}\left(r_{m}^{\prime}\right.$, active membrane resistance for unit length The high values of these quantities in normal state, satisfying the conditio 
with ample reserve, may be appreciated in this view. ${ }^{3)}$ Reduction of these values, if occurs, will reduce the safety, modifying type I towards II.

2) Judgement from the safety factor of propagation, $F$

$\mathrm{F}$ is a direct measure for the safety under consideration and is known to be so large as about $5^{81}$ in normal myelinated fibres. Now, in the present theory, conduction is distinguished from excitation, hence the safety factor of conduction, $\mathrm{F}$, from that of excitation, $f$. How is then $\mathrm{F}$ related with $f$ generally, and how does it change in abnormal conditions?

Let us consider the later stage of conduction, where the action length is fully developed, accordingly, $x>k^{\prime}$. Then, for unmyelinated fibres, eq. (1) turns into

$$
\mathrm{y}=\mathrm{k} \ln f=\mathrm{k} \ln \frac{\mathrm{V}}{\mathrm{S}}\left(=\frac{\sqrt{\mathrm{r}_{\mathrm{m}}}}{\sqrt{\mathrm{r}_{\mathrm{i}}}} \ln \frac{\mathrm{V}}{\mathrm{r}_{\mathrm{m}} \mathrm{s}_{\mathrm{s}}}\right)=\text { const. }
$$

Now, y for $\frac{\mathrm{V}}{\mathrm{F}}$ should be $\mathrm{L}$, so

$$
\mathrm{L}=\mathrm{k} \ln \frac{\mathrm{V}}{\mathrm{FS}} ; \mathrm{e}^{\mathrm{L} / \mathrm{k}}(=m)=\frac{f}{\mathrm{~F}} ; \text { hence, } \mathrm{F}=\frac{f}{m}
$$

Normally, $m$ is just slightly larger than unity (see App. 1, note 1), hence $\mathrm{F} \fallingdotseq f$, that is, $f$ can represent $\mathrm{F}$.

In myelinated fibres, practically just one active node acts as the stimulator as stated above; and y for $\frac{\mathrm{V}}{\mathrm{F}}$ should be $(d+\mathrm{L}) \fallingdotseq d(d$, internodal length). Hence, from eq. (1)

$$
d=\mathrm{k}_{\mathrm{s}} \ln \frac{\theta f}{\mathrm{~F}} ; \mathrm{F} \fallingdotseq \theta f \mathrm{e}^{-\mathrm{d} / \mathrm{k}_{\mathrm{s}}}
$$

$\mathbf{k}_{\mathrm{S}}$, length const. of sheath membrane; $d$, internodal length; $\theta=\left(\mathrm{l}-\mathrm{e}^{-\mathrm{b} / \mathrm{k}^{\prime}}\right) ; b$, nodal breadth, $\fallingdotseq 0.5 \mu^{103}$

Evidently, $\mathrm{F}<f$ generally. In frogs, for example, $d \fallingdotseq 2 \mathrm{~mm}$. and $\mathrm{k}_{\mathrm{s}} \fallingdotseq 5 \mathrm{~mm}$. (estimated from data in Stämpfli's table $\left.{ }^{11}\right)$, hence $\mathrm{F} \fallingdotseq 0.7 f$ even if $\theta=1$. If adopted $\mathrm{F} \fallingdotseq 5$ obtained by the air-gap method, then $\mathrm{F} \fallingdotseq 0.5 f$, because $\mathrm{F} \fallingdotseq 5$ indicates $f \fallingdotseq 10$, if taken (internal axonal resistance) $\fallingdotseq$ (nodal membrane resistance). In normal conduction, however, $F$ must be much smaller, because $\theta \fallingdotseq 0.3$, as will be stated later.

Thus, the myelination generally changes $\mathrm{F} \fallingdotseq f$ to $\mathrm{F}<f$. But at the same time, the length constant is enlarged practically from that of the nodal membrane ( $\fallingdotseq 0.05 \mathrm{~mm}$., estimated from Stämpfli's table ${ }^{11)}$ ) to that of the sheath ( $\fallingdotseq 5 \mathrm{~mm}$.). This will enlarge the conduction velocity, about which see next chapter.

How $\mathrm{F}$ changes in abnormal conditions, will be seen from eq. (3) and 
(4), respectively.

3) Judgement from the liminal gradient

The liminal gradient for initiation of impulse in frog's myelinat fibres is said to be $0.1-1.0 \mathrm{mV} / \mathrm{msec}^{12)}$ or $0.8-6 \mathrm{~V} / \mathrm{sec}^{13)}$ The val required from the present theor ${ }^{5}$ is about the same with Tasaki's. ${ }^{12}$ No' the gradient of the action potential in the rising phase is about $100 \mathrm{mV} / 0$ msec., that is, about $10^{2-3}$-times greater than the liminal. The safe of propagation in this view being thus almost complete, some reductic of the slope will not matter at all. Rudolph's interpretation for the o served block ${ }^{14}$ ) becomes then somewhat doubtful. The true cause of $\left.t\right]$ block might have been some other event which took place simultaneously

\section{The Conduction Velocity}

\section{1) Unmyelinated fibres}

The eq. (1) represents the resting length $y$ to be excited by $x, b_{1}$ does not contain the time factor necessary for it. So, no discussion ce be developed therefrom on the conduction velocity, $v$. However, if $v$ confine our attention to the later stationary stage of conduction whe $y=$ const. (eq. (2)), we may represent the relative velocity by $y$ itse assuming the time factor constant.

a) Relation to stimulation intensity and conduction distance. $\mathbf{E}$ (2) indicates directly that as long as observation is made at distant place $\mathrm{y}$ is determined by $\mathrm{k}$ and $f$ only; that is, that $v$ is independent of stimul intensity and conduction distance, as is well known since old times.

b) Relation to fibre size. Let the diameter be R. Then, $r_{m} \propto \frac{1}{R}$; $\propto \frac{1}{\mathrm{R}^{2}} ; \mathrm{i}_{\mathrm{s}} \propto \mathrm{R} ; \mathrm{V}=$ const. Hence $\mathrm{k} \fallingdotseq \sqrt{\frac{\mathrm{r}_{\mathrm{m}}}{\mathrm{r}_{\mathrm{i}}}} \propto \sqrt{\mathrm{R}} ; f=\frac{\mathrm{V}}{\mathrm{r}_{\mathrm{m}} \mathbf{i}_{\mathrm{s}}}=$ const. ; a cordingly $\mathrm{y}(v) \propto \sqrt{\mathrm{R}}$. This conclusion involves the assumption $\mathrm{k}$ : $\sqrt{\frac{r_{m}}{r_{i}+r_{e}} \fallingdotseq \sqrt{\frac{r_{m}}{r_{i}}}}\left(r_{e}\right.$, external resistance per unit length). Under the san assumption, Hodgkin ${ }^{15)}$ too obtained $v \propto \sqrt{\mathrm{R}}$, which, prior to him, w. verified experimentally by Pumphrey-Young ${ }^{16)}$. Hodes ${ }^{17}$ says, hov ever, that this is an experimental mistake, and the correct relation is $v \propto l$ The matter is not yet quite clear.

c) Relation to membrane resistance. As a function of $r_{m}, y$ eq. (2) attains maximum at $\mathrm{r}_{\mathrm{n}}=\frac{1}{\mathrm{e}^{2}} \frac{\mathrm{V}}{\mathrm{i}_{\mathrm{s}}}$, that is, at $f\left(=\frac{\mathrm{V}}{\mathrm{r}_{\mathrm{m}} \mathrm{i}_{\mathrm{s}}}\right)=\mathrm{e}^{2} \fallingdotseq 8^{3)}$, und given $\mathrm{V}$ and $i_{\mathrm{s}}$. It is note-worthy that this is not far from $f \fallingdotseq 10$, whic was estimated for the nodal membrane.

Hitherto, large $r_{m}$ has been interpreted simply as a mechanism $f_{i}$ 
enhancing $v$ by enlarging $\mathrm{k}$. The above consideration suggests that there is a limit in the validity of the interpretation. The point is that only the distribution of potential and not of the current as stimulus has been considered. Unfortunately we cannot test the above conclusion experimentally, because we have no proper method of modifying just $r_{m}$, keeping other features unchanged.

2) Myelinated fibres

a) Relative $v$. The length constant $\mathrm{k}$ of a nodal membrane is about $0.05 \mathrm{~mm}$. while the breadth about $0.5 \mu$, as stated before; hence, the potential drop along a single membrane is just about $1 \%$. We may neglect this drop and take a fibre as covered uniformly by a sheath membrane, as far as the current distribution is concerned. Taking just one active node as the stimulator as before, and supposing the internodal portion to be excitable too for convenience, we have from eq. (1)

$$
\mathrm{y}=\mathrm{k}_{\mathrm{s}} \ln \frac{\theta \mathrm{V}}{\mathrm{S}}=\mathrm{k}_{\mathrm{s}} \ln \theta f, \quad \theta=\text { const...................... }
$$

Eq. (5) is just the same in form with eq. (2), so that the arguments developed on relative $v$ of unmyelinated fibres are available also for myelinated. Points of notice are that 1) activity takes place only at nodes inside y, 2) $f$ is invariably that of the nodal membrane, so that 3 ) y, being simply proportional to $k_{s}$, gives no maximum for variable sheath-resistance.

Now, if $\mathrm{k}$ and $f$ of eq. (2) are taken those of the nodal membrane, the equation represents y of an imaginary unmyelinated fibre which is covered uniformly by the nodal membrane. Introducing $\mathrm{k} \fallingdotseq 0.05 \mathrm{~mm}$. and $f \fallingdotseq 10$, we have $y \fallingdotseq 0.12 \mathrm{~mm}$. By comparing this with y of eq. (5), representing an actual myelinated fibre, we can clarify the role of myelination as regards $v$. Unfortunately, the correct value of $\mathrm{k}^{\prime}$, accordingly of $\theta$ is unknown (see App. 1), so that theoretical evaluation of y of eq. (5) is impossible. However, we know the fact that excitation of a node jumps over 1-2 resting nodes ${ }^{11,18)}$. This shows that $4 \mathrm{~mm} .<y<8 \mathrm{~mm}$. or $y \fallingdotseq 6 \mathrm{~mm}$. in average ; in other words that y of eq. (5) is about $6 \mathrm{~mm}$ in actuality (The length of narcotized regions necessary for block-making is known to be about $6 \mathrm{~mm}$, too). Then we have $\frac{6}{0.12}=50$, which, expressing that $\mathrm{y}(v)$ of an actual myelinated fibre can be, although not exact, about 50 -times greater than that of an imaginary unmyelinated, makes us see how effective the myelination is for enhancing $v$. It may be remembered here that squid's giant axon and frog's myelinated fibre are almost equally quick, inspite of the great difference in diameter $(500: 10)$ and the similar values of the action potential.

On the other hand, $\mathrm{F}$ is reduced greatly by myelination, as stated 
before. The myelination appears thus to be a means for enhancing $v$ a the cost of F.

b) The value of $F$. Introducing $k_{\mathrm{s}} \fallingdotseq 5 \mathrm{~mm}$. and $y \div 6 \mathrm{~mm}$. int eq. (5), we have $\theta f \fallingdotseq \mathrm{e}^{1.2}$. This introduced into eq. (4), together wit $\mathrm{k}_{\mathrm{s}} \fallingdotseq 5 \mathrm{~mm}$. and $d \fallingdotseq 2 \mathrm{~mm}$., gives $\mathrm{F} \fallingdotseq \mathrm{e}^{1.2-0.4} \fallingdotseq 2.1$. The evaluation is neve exact, but it should be noticed that $\mathrm{F}$ thus obtained is very much smalle than $\mathrm{F} \fallingdotseq 5$ obtained by the air-gap method, which, checking the curren leak from the internode, must have given a somewhat larger $F$ than $i$ : normal conduction. Experimental examinations are desired.

Note. From $\theta f \fallingdotseq \mathrm{e}^{1.2} \fallingdotseq 3$ and $f \fallingdotseq 10$, we have $\theta \fallingdotseq 0.3$.

c) Absolute $v$. Hodler et al. ${ }^{19)}$ and Tasaki ${ }^{20)}$ claimed that the inter nodal conduction time is nothing but the time for potential spreadin along an internode as a physical cable. They think that the reductio: of $v$ in low temperature is due to elongation of this time resulting from ris of the resistance. Certainly, some time must be needed for potentic spreading, but the point is how much. If no time is spent at the node as they think, then $v$ will be independent of the internodal distance, $\mathrm{c}$ rather larger in case of shorter internodal distance. Further, in the trans mission via air-gap where about one half of the action potential is impresse upon the resting node, the measured conduction time is about $0.1 \mathrm{msec}$ that is, about the same with the actual one in normal conduction. Th: fact seems to indicate that the normal conduction time is largely, thoug not all, spent at the nodes for their excitations. If so, $v$ should depen upon the internodal length. Let us examine it below, neglecting the tim for potential spreading on purpose.

Suppose the node $\mathrm{N}_{1}$ excited (Fig. 2). The action potential, spreadin as shown in the figure, acts upon the resting node $\mathrm{N}_{2}$ with the intensit $P_{d}$. Taking the action potential constant for simplicity, we may regar the case as one of the direct current stimulation, where the equation $\eta I=$

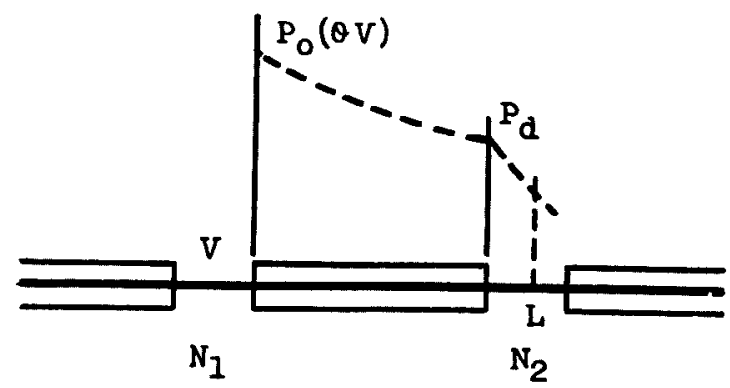

Fig. 2. Spreading of action potentia lalong a myelinated fibre, schematic. $N_{1}$, active node; $N_{2}$, resting node; $V$, action potential ; $P_{0}, P_{d}$, potentials at both ends of internode. 
$\frac{I_{r}}{1-e^{-t / \alpha}}\left(t \leqq t_{r}\right)^{4)}$ holds for initiation of impulse. Replacing $I$ and $I_{r}$ with $P_{d}$ and $P_{r}$ (the smallest value of $P_{d}$ effective for propagation) respectively, we have

$$
\eta \mathrm{P}_{\mathrm{d}}\left(=\eta \mathrm{P}_{\mathrm{o}} \mathrm{e}^{-\mathrm{d} / \mathrm{k}_{\mathrm{s}}}=\eta \theta \mathrm{V} \mathrm{e}^{-\mathrm{d} / \mathrm{k}_{\mathrm{s}}}\right)=\frac{\mathrm{P}_{\mathrm{r}}}{1-\mathrm{e}^{-\mathrm{t} / \alpha}}, \mathrm{t} \leqq \mathrm{t}_{\mathrm{r}}
$$

which gives $\mathrm{t}=\alpha \ln \frac{\eta \mathrm{P}_{\mathrm{d}}}{\eta \mathrm{P}_{\mathrm{d}}-\mathrm{P}_{\mathrm{r}}}=-\alpha \ln \left(1-\frac{\mathrm{P}_{\mathrm{r}}}{\gamma \theta \mathrm{V}} \mathrm{e}^{\mathrm{d} / \mathrm{k}_{\mathrm{s}}}\right)$

We may take $P_{r} \fallingdotseq \frac{30}{3} \mathrm{mV}$, because the rheobasic potential for initiation of impulse in node-to-node stimulation via air-gap is about $30 \mathrm{mV}$, and the nodal membrane resistance is about equal to the internodal axonal. Then, introducing $\alpha \fallingdotseq 0.5 \mathrm{msec} ., \quad \mathrm{V} \fallingdotseq 100 \mathrm{mV}, \mathrm{k}_{\mathrm{s}} \fallingdotseq 5 \mathrm{~mm} ., \eta \fallingdotseq 1$ and $\theta \fallingdotseq$ 0.3 , we have

$$
v=\frac{d+b}{\mathrm{t}}(b, \text { nodal breadth }) \fallingdotseq-\frac{d}{\log \left(1-0.3 \mathrm{e}^{d / 5}\right)}
$$

The result of computation is as follows:

\begin{tabular}{c|l|l|l|l|l|l|l|l}
\hline$d(\mathrm{~mm})$ & 0.5 & 1 & 2 & 3 & 4 & 5 & 5.5 & 6 \\
\hline$v(\mathrm{~mm} / \mathrm{msec})$ & 2.9 & 5.0 & 7.7 & 8.8 & 8.3 & 6.8 & 5.5 & 2.5
\end{tabular}

It is quite interesting and note-worthy that $v$ has a relatively flat maximum at $d \fallingdotseq 3 \mathrm{~mm}$. The obtained maximal velocity is too small compared to the actual, but it is probably because of the inexactness of the values of the physiological data employed, particularly of $\theta$. If $\theta$ is taken 0.5 instead of 0.3 (which is not improbable), then we have $v \fallingdotseq 20 \mathrm{~mm} / \mathrm{msec}$ at $d=3$ $\mathrm{mm}$. Thus, in the light of the present theory, the myelinated fibres appear to be provided with two efficient mechanisms as regards $v$, namely, 1) $f \fallingdotseq 10$ of the nodal membrane, showing that the membrane is made so resistent as to make $v$ in it nearly maximal under given $V$ and $i_{s}$, and 2) a proper internodal length, enhancing $v$ greatly, if not most, effectively.

IV. Effect of Temperature

1) Variation of $D$ and its significances

a) In the node-to-node stimulation in low temperature, $V_{r}$ remains practically constant, while the liminal gradient $\beta_{\mathrm{r}}$ decreases enormously ${ }^{12}$. As one of the possible causes, some reduction of $m$ was supposed to occur in a previous paper ${ }^{6}$, but there was a confusion arising from mistaking $\mathrm{V}_{\mathrm{r}}$-constancy as $\mathrm{I}_{\mathrm{r}}$-constancy.

From $\left.\mathrm{I}_{\mathrm{r}}=m r_{i} i_{r}{ }^{4}\right)$ and $\beta_{\mathrm{r}}=\frac{\mathrm{I}_{\mathrm{r}}(m-1)}{m_{r} \mathrm{D}}(\mathrm{Amp} / \mathrm{sec}),{ }^{5)}$ we have 
$\begin{array}{ll}\mathrm{V}_{\mathrm{r}}=\mathrm{aWI} & \fallingdotseq \mathrm{aWmi} i_{r}(\eta \doteqdot 1, \text { assumed }) \ldots \ldots \ldots \ldots \ldots \ldots \ldots \ldots \ldots \\ \text { and } \quad & \beta_{\mathrm{r}}=\frac{\mathrm{aWI}}{m_{\eta}(m-1)} \fallingdotseq \frac{\mathrm{V}_{\mathrm{r}}(m-1)}{m \mathrm{D}}(\text { Volt } / \mathrm{sec})(\eta \fallingdotseq 1, \text { assumed }) \ldots\end{array}$

$\mathrm{W}, \mathrm{aI}_{\mathrm{r}}$, total resistance and current respectively in stimulating circuit ;

a, proportionality factor.

In low temperature, $r_{m}$ and $r_{i}$ rise similarly $\left(Q_{10} \fallingdotseq 2 \text { for both }\right)^{2}$ hence, $\mathrm{W} \propto \mathrm{r}_{\mathrm{m}}$; accordingly, if $\mathrm{W} i_{r}$ increases (or decreases), then $\mathrm{r}_{\mathrm{m}} i_{r} \mathrm{i}$ creases (or decreases) parallel with it, which in turn increases (or $\mathrm{d}$ creases) $m$ (see eq. (9)). As the result, $\mathrm{V}_{\mathrm{r}}$ must become larger (or smalle in contradiction to the observed fact. In actuality, therefore, $\mathrm{W} i_{r}\left(\mathrm{r}_{\mathrm{m}} i\right.$ accordingly $m$, must remain about constant. If thus $\mathrm{V}_{\mathrm{r}} \fallingdotseq$ const. and $m$ const., then $\beta_{\mathrm{r}}$ should vary simply with $\mathrm{D}$ in inverse manner (see eq. ( 7 ), This is in accord with $\mathrm{D}$-prolongation in low temperature, which is lar enough $\left(Q_{10} \fallingdotseq 3.3^{22}\right)$ ) to explain the actual reduction of $\beta_{\mathrm{r}}$ satisfactorily

b) Tasaki ${ }^{23)}$ observed hysteresis-effect of temperature upon $\beta_{r}$, al Schriever ${ }^{24)}$ some temporal variation of $\beta_{\mathrm{r}}$ under constant temperatu where $V_{r}$ and $\tau$ (chronaxie) were constant. In view of the present theor the observed facts on $\beta_{r}$ are comprehensive as resulting from delay, effect of temperature upon $\mathrm{D}$, and the constancy of $\mathrm{V}_{\mathrm{r}}$ and $\tau$ as due small effect of $\mathrm{D}$ upon these quantities (see eq. (6) above and eq. (7) the previous paper $\left.{ }^{4}\right)$.

2) Reduction of $v$ in low temperature

As mentioned above, $r_{m}$ and $r_{i}$ change nearly proportionally, hen $\mathrm{k} \fallingdotseq$ const. In addition, $\mathrm{V} \fallingdotseq$ const. and $\mathrm{r}_{\mathrm{m}} i_{r} \fallingdotseq$ const., accordingly $f \fallingdotseq$ con Therefore, we should expect $\mathrm{y}(v) \fallingdotseq$ const. from eq. (2). If Fatt-Kat: data $\left(Q_{10(\mathrm{rm})}=2.5 ; Q_{10(\mathrm{ri})}=1.2\right)$ are adopted, y should be even larger low temperature. In fact, however, $v$ decreases greatly in apparent co tradiction to the theory. In low temperature, however, the action curre must be very weak, because $\mathrm{V}$ is practically unchanged while the loc circuit resistance enormously raised. In addition, the stimulatory proce of whatever nature it may be, must proceed slowly. Tasaki ${ }^{23)}$ not on proved this slowness but also discovered that thereby the electrical quanti necessary for excitation increases enormously $\left(Q_{10} \doteqdot 1.7\right)$. These togeth will lengthen the time for completion of stimulation, which should result reducing $v$. It is interesting to note in this connexion that $\left.Q_{10} \fallingdotseq 1.7\right) f$ the necessary electrical quantity above cited is about the same with $Q$ of $v(\fallingdotseq 1.8)^{22)}$; further that $\mathrm{D}$ is prolonged, perhaps to supply amr time and energy for stimulation.

We may say after all that "y might be unchanged or even larger low temperature, but the time necessary for exciting it will become larg to make $v$ smaller." The electrical nature of conducting stimulus $h$ 
been fully evidenced ${ }^{26}$, but the process which follows the current flow must be of a complicated chemical or physico-chemical nature, which must be influenced by temperature a great deal.

\section{Block-making}

\section{1) By electrotonus (E.T.)}

Modification of $v$ under E.T. is well known, but precise discussion on it is impossible, because details are unknown about the changes of $V, r_{m}$, $r_{i}, i_{s}$ etc. under E.T. of various intensities and durations. The only fact which can be treated with certainty, may be that of block which takes place in strong E.T.

In strong C.E.T., a small rise of $V_{r}$ and a violent fall of $V$ take place, while in strong A.E.T. a small rise of $V$ and a violent rise of $V_{r} \cdot{ }^{27,28}$ ) As the result, $F$ gets smaller and smaller until finally block occurs at $F=1$ in both cases. Now, $\mathrm{F}=\frac{f}{m}$ (eq. (3)) and $\mathrm{F} \fallingdotseq \theta f \mathrm{e}^{-d / \mathrm{k}_{\mathrm{s}}}$ (eq. (4)) in unmyelinated and myelinated fibres, hence block occurs respectively at $f=m$ and $f \fallingdotseq \frac{1}{\theta} \mathrm{e}^{d / \mathbf{k}_{\mathrm{s}}}$. This means that $f$ is still larger than unity by an amount at the moment of block, that is to say, conduction block in general is not always excitation block.

2) By narcosis

a) Unmyelinated fibres. First, consider a fibre wholely narcotized. As $r_{m}$ remains practically constant, ${ }^{18,20)} \mathrm{k}$ and perhaps $\mathrm{k}^{\prime}$ will do so, too. Then, as the result of $\mathrm{V}$-, accordingly of $f$-decrease, the type of $y$-x-relation will change from I to II, and the conduction from decrementless to decremental to become finally just local. ${ }^{1)}$ The matter is the same when an impulse transits from normal to narcotized region, because there is no difference in condition except that the intensity of the stimulus acting upon the narcotized region is invariable. The length, $X$, of the narcotized part necessary for block-making is estimated from

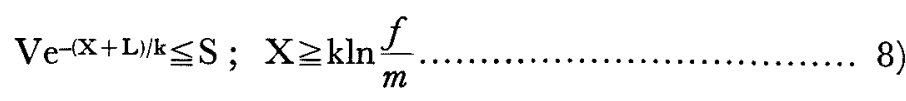

For the squid's giant axon, for example, we have $\mathrm{X} \geqq 14 \mathrm{~mm}$., if taken $\mathrm{k} \fallingdotseq 6 \mathrm{~mm}$., $m \fallingdotseq 1$, and $f \fallingdotseq 10$ as in the nodal membrane.

b) Myelinated fibres. The type of y-x-relation of the nodal membrane will change from I to II with progress of narcosis, but it is always possible to excite a "whole" node by a proper stimulus. An impulse will be initiated as long as a node thus activated can excite the next " whole" node. The matter is the same in the case of transition from normal to narcotized region. Whether an impulse passes through or not depends 
upon whether the activity of a narcotized node can excite the following narcotized node as a whole, or not.

Now, in order that a node can excite the next node as a whole, the activity of the former must excite " $\mathrm{L}$ " of the latter, and, furthermore, $\mathrm{L}$ must be smaller than $b$, the nodal breadth. For, if $\mathrm{L}>b$, the case of single node activity corresponds to that of $\mathrm{x}<\mathrm{L}$ in eq. (1), so that no impulse can be initiated even if there were no internode. It seems certain that the normal $\mathrm{L}$ is smaller than $b$, as stated before, but it will grow with progress of narcosis and tend to $\mathrm{L} \geqq b$, to bring forth block at a certain stage.

3) Cold block

There are not sufficient data for discussing the matter quantitatively, so the arguement is only speculative.

As stated above, reduction of $v$ in low temperature is comprehensive as the result of elongation of the excitation time, but the fact of block not. For understanding this, we have to consider fall of $f\left(=\frac{\mathrm{V}}{\mathrm{r}_{\mathrm{m}} \mathrm{i}_{\mathrm{s}}}\right)$ towards unity, because $\mathrm{k}$ remains about constant or gets larger in eq. (2), as stated before. Now, fall of $f$ must be due to enlargement of $r_{m} i_{s}$, because $V \fallingdotseq$ const. ; and, enlargement of $r_{m} i_{s}$ (that is, of $r_{m} i_{r}$ ), if occurs, enlarges $W i_{r}$ and $m$ as stated before ; as a consequence, we should first expect rise of $V_{r}$ from eq. (6) in very low temperature. Next, enlargement of $r_{m} i_{r}$ must be due to relatively less reduction of $i_{r}$ in comparison to $\mathrm{r}_{\mathrm{m}}$-increase; and relatively less reduction of $i_{r}$ may possibly be due to relatively less prolongation of $\mathrm{D}$ in very low temperature. Thus, experimental examinations of $\mathrm{V}_{\mathrm{r}}$ and $\mathrm{D}$ may be clues for clarifying the matter.

\section{SUMMARY}

The principle of initiation of impulse derived theoretically by myself was applied to various phenomena of conduction. As the result, many experimental facts could be understood or explained quite reasonably. A few suggestions were obtained, too.

\section{APPENDIXES}

1) Derivation of $P_{\mathrm{y}=\mathrm{o}}$ (Fig. $1, A$ ) and the value of $k^{\prime}$

For deriving eq. (1), it was first assumed ${ }^{2}$

$$
\mathbf{P}_{\mathrm{y}=0}=\int_{0}^{\mathrm{x}} \alpha \mathrm{Ve}^{-\mathrm{x} / \mathrm{k}^{\prime}} \mathrm{d} \mathbf{x}, \quad \begin{aligned}
& \mathbf{P}_{\mathrm{y}=0}, \text { potential at } \mathrm{y}=0 ; \\
& \alpha, \text { proportionality factor. }
\end{aligned}
$$

Introducing the condition $P_{y=0}$ (for $\left.x=\infty\right)=V$ into it, we obtained $P_{y=0}$ $\fallingdotseq \mathrm{V}\left(1-\mathrm{e}^{-\mathrm{x} / \mathrm{k}^{\prime}}\right)$. The method may be open to question, but the result seems to be reasonable, at least qualitatively, showing $P_{y=0}$ growing from zero towards a definite value, $V$. The point is the value of $\mathbf{k}^{\prime}$. If as- 
sumed $\mathrm{k}^{\prime} \fallingdotseq \sqrt{\frac{\mathrm{r}_{\mathrm{m}}{ }^{\prime}}{\mathrm{r}_{\mathrm{i}}} \fallingdotseq \mathrm{k}} \sqrt{\frac{\mathrm{r}_{\mathrm{m}}{ }^{1)}}{\mathrm{r}_{\mathrm{m}}}}$ and $\frac{\mathrm{r}_{\mathrm{m}}{ }^{\prime}}{\mathrm{r}_{\mathrm{m}}} \fallingdotseq \frac{1}{40}$ for both squid's giant axon and frog's nodal membrarie, then we have $\mathrm{k}^{\prime} \fallingdotseq 1 \mathrm{~mm}$. for the former where $\mathrm{k} \fallingdotseq$ $6 \mathrm{~mm}$., and $\mathrm{k}^{\prime} \fallingdotseq 8 \mu$ for the latter where $\mathrm{k} \fallingdotseq 50 \mu$.Then, to have $\mathrm{P}_{\mathrm{y}=\mathrm{o}} \fallingdotseq \mathrm{V}$, $\mathbf{x}$ must be larger than about $5 \mathrm{~mm}$. in the case of squid, which seems doubtful. Further, in frog's myelinated fibres where practically just one active node acts as the stimulator, we ought to have $\mathrm{P}_{\mathrm{y}=0}=\mathrm{V}\left(1-\mathrm{e}^{-0.5 / 8}\right)$ $\fallingdotseq 0.06 \mathrm{~V}$. If $\frac{\mathrm{r}_{\mathrm{m}}^{\prime}}{\mathrm{r}_{\mathrm{m}}}>\frac{1}{40}$ (Tasaki-Freygang says that $\frac{\mathrm{r}_{\mathrm{m}}^{\prime}}{\mathrm{r}_{\mathrm{m}}}<\frac{1}{10}{ }^{29)}$ ), $\quad \mathrm{P}_{\mathrm{y}=\mathrm{o}}$ will be still smaller, which is evidently incompatible with $\mathrm{F}(\fallingdotseq 5)$ or $f(\fallingdotseq 10)$.

Now, as to the nodal membrane, a much smaller $\mathrm{k}^{\prime}$ is obtainable from $\theta \fallingdotseq 0.3$ evaluated before. Introducing this and $b \fallingdotseq 0.5 \mu$ into $\theta=$ $1-\mathrm{e}^{-b / \mathrm{k}^{\prime}}$, we have $\mathrm{k}^{\prime} \fallingdotseq 1.5 \mu$. We take this much more reliable, because it is based on the facts $\mathrm{y} \fallingdotseq 6 \mathrm{~mm}$. and $f \fallingdotseq 10$ (see p. 93).

Note 1. Taking $\mathrm{L} \fallingdotseq l$ for approximation (see Fig. 1 and legend), we have $\mathrm{L} \fallingdotseq \mathrm{k}^{\prime} / f \fallingdotseq 0.15 \mu$ from eq. (1), and $m=\mathrm{e}^{\mathrm{L} / \mathrm{k}} \fallingdotseq \mathrm{e}^{0.15 / 50} \fallingdotseq 1.003$ for $\mathrm{e}^{0.8 / 50} \fallingdotseq 1.02$ obtained before ${ }^{4}$.

Note 2. The theoretical values of $t_{r}, \beta_{r}$, $\tau$ etc. were still in approximate agreement with the experimental, when corrected by adopting $\mathrm{m} \fallingdotseq 1.003$.

Note 3. The value of $\theta(\fallingdotseq 0.3)$, is backed up by facts, but $P_{0}(=\theta \mathrm{V})$ appears to be too small if judged from the resistance of the sheath membrane which is enormous compared to that of an active nodal membrane. The actual state of affairs is not clear, but possibly some juxta-nodal portion of the sheath may be much less resistent than the central portion.

2) The value of $m=e^{\mathrm{L} / \mathbf{k}}$ in general

The factor $m$ which plays an essential role in initiation and propagation of impulse, may be termed the "constant of propagation". Its value is determined by $\frac{\mathrm{L}}{\mathrm{k}}$, which varies according to conditions. It is very small normally, so we may put $m \fallingdotseq 1+\frac{\mathrm{L}}{\mathrm{k}}$. If taken $\mathrm{L} \fallingdotseq \frac{\mathrm{k}^{\prime}}{f}$ as above, then $\frac{\mathrm{L}}{\mathbf{k}} \fallingdotseq \frac{\mathbf{k}^{\prime}}{\mathbf{k}} \frac{\mathbf{l}}{f}$, that is

$$
\frac{\mathrm{L}}{\mathrm{k}}(\fallingdotseq \mathrm{m}-1) \propto \frac{1}{f}\left(\text { or } \frac{\mathrm{r}_{\mathrm{m}} \mathrm{i}_{\mathrm{s}}}{\mathrm{V}}, \text { or } \frac{\mathrm{r}_{\mathrm{m}} i_{r}}{\mathrm{~V}}\right)
$$

if assumed $\frac{\mathbf{k}^{\prime}}{\mathrm{k}}=$ constant.

This conclusion is not exact but very interesting and important, showing that $(m-1)$, accordingly $\beta_{\mathrm{r}}$ (eq. (7)), is inversely proportional to $f$ approximately. It also enables us to judge the gross tendency of $m$ variation in various conditions.

3) Local response (L.R.)

The so-called L.R. of nerve fibres discovered by $\mathrm{Katz}^{30)}$ was first taken 
as an all-or-none response of a minute area in connexion with Rushton's theory ${ }^{31)}$, and then, after Marmont ${ }^{32)}$, as a subthreshold activity of any area. The present theory has nothing to do directly with this problem, because it takes just the all-or-none activity of various areas into consideration. However, as stated and discussed previously ${ }^{1)}$, the graded L.R. is well comprehensive as a spatial event inside $\mathrm{L}$ from the present theory, and, on the other hand, Marmont's observation does not always prove the subthreshold activity. For, in stimulation of a large area as in Marmont, some "islands" of excitation will appear in weak stimulation as a result of physical and physiological ununiformities of the membrane, which, growing in number and area and thus giving graded L.R. as a whole, will suddenly be led to propagation and fusion at a certain stimulus intensity.

Just recently, some very similar ideas have appeared, namely, the ideas of active "spot" or " unit" or "patch" presented by Grundfest, ${ }^{33)}$ Tasaki-Hagiwara ${ }^{34)}$ and perhaps also del Castillo-Suckling ${ }^{35)}$. Grundfest argues that observed action potential should increase with number of active units, that is, with stimulus intensity. Perhaps the same thing is considered in del Castillo-Suckling who say that the gradation of the L.R. of a single node is "quantal". Tasaki-Hagiwara claim that, in the socalled threshold excitation, the total area of the active spots should attain a certain fraction of the stimulated area. In all of them, the activity of a spot is considered to be all-or-none. Evidently, they all think, after all, of an area of full-sized activity growing with stimulus, and to this they appear to relate the graded nature of L.R. Another point to be noticed is that each active spot is supposed to stand isolated. This is nothing but an expression of the idea that a too small active area cannot initiate an impulse. In these points, their ideas are just the same with mine. The only but not essential difference is that I took the current distribution ununiform (expotential) and the membrane condition uniform, for simplicity, in usual method of stimulation. In other words, I considered of " an" active area growing with stimulus, while they active spots growing in number.

Nothing has been said about the dimension of the "spot", but presumably it must be of an ultramicroscopic or a still smaller order. Besides such a fine structural unit, I imagine another, so to speak, "functional" unit, a certain assembly of the former, to exist" ${ }^{11}$. Its dimension is supposed to vary according to conditions. The liminal length " $\mathrm{L}$ ", for example, may be one, and the node of Ranvier another, of the latter kind of units, in respective senses.

Finally, the possible dependence of the graded L.R. upon " area " is most simply understood in the following way: the measurement of the action potential is usually carried out under the flow of the local current 
covering active and resting regions. Even if an intracellular electrode is employed, the measured potential cannot exceed the so-called terminal voltage, which gets smaller with larger internal resistance of the source battery. It is then natural that the measured potential gets smaller with smaller active area, which possesses larger resistance.

Besides such a L.R. of spatial nature, there might exist the so-called subthreshold activity, too. But in order to distinguish it from the former, it must be verified as an event in a final structural unit above stated, or at least a proper method must be invented for stimulating an area, minute enough to be uniform, under strict limitation. The final decision of the matter seems to be exrtremely difficult.

\section{References}

1) Yamagiwa, K., Jap. J. Physiol., 1955, 5, 131.

2) Yamagiwa, K., ibid., 1955, 5, 317.

3) Yamagiwa, K., ibid., 1956, 6, 167.

4) Yamagiwa, K., Tohoku J. exp. Med. 1957, 66, 153.

5) Yamagiwa, K., ibid., 1957, 66, 163.

6) Yamagiwa, K., ibit., 1957, 66, 175.

7) Yamagiwa, K., Jap. Med. J., 1948, 1, 439.

8) Tasaki, I., Nervous Transmission. Charles C. Thomas, Springfield, 1953.

9) Yamagiwa, K., Bulletin Tokyo Med. \& Dental Univ., 1954, 1, 133.

10) Stämpfli, R., Physiol. Rev., 1954, 34, 101.

11) Stämpfli, R., Ergeb. Physiol., 1953, 47, 70.

12) Tasaki, I., Cytologia, 1950, 15, 219.

13) Diecke, F., Z. Naturf. 1954, 9b, 713.

14) Rudolph, G., Ann. universitatis Saraviensis, 1956, IV, I, I.

15) Hodgkin, A. L., J. Physiol., 1954, 125, 211.

16) Pumphrey, R.J. \& Young, J.S., J. exp. Biol., 1938, 15, 453.

17) Hodes, R., J. Neurophysiol., 1953, 16, 145.

18) Tasaki, I., Shinkei Sen-i no Seirigaku (Jap.), Tokyo, Kawai, Co., 1944.

19) Hodler, J., Stämpfli, R. \& Tasaki, I., Pflüg. Arch., 1951., 253, 380.

20) Tasaki, I., Amer. J. Physiol., 1955, 181, 639.

21) Tamashige, M., Ann. Zool. Jap., 1950, 23, 125.

22) Tasaki, I. \& Fujita, M., J. Neurophysiol., 1948, 11, 311.

23) Tasaki, I., Biochimica et biophysica Acta, 1949, 3, 498.

24) Schriever, H., Z. Biol., 1932, 93, 123.

25) Fatt, P. \& Katz, B., J. Physiol., 1953, 120, 179.

26) Hodgkin, A. L., J. Physiol., 1937, 90, 183, 211.

27) Tasaki, I. \& Takeuchi, T., Pflüg. Arch., 1944, 246, 32.

28) Tasaki, I., Mizuguchi, K. \& Tasaki, K., J. Neurophysiol., 1948, 11, 305.

29) Tasaki, I. \& Freygang, W.H. Jr., J. Gen. Physiol., 1955, 39, 211.

30) Katz, B., Proc. Roy. Soc. B., 1937, 124, 244.

31) Rushton, W.A.H., Proc. Roy. Soc. B., 1937, 124, 210.

32) Marmont, G., J. Cell. Comp. Physiol., 1949, 34, 351.

33) Grundfest, H., Physiol. Rev., 1957, 37, 337.

34) Tasaki, I. \& Hagiwara, S., J. Gen. Physiol., 1957, 40, 859.

35) del Castillo, J. \& Suckling, E. E., Fed. Proc. 1957, 16, 29. 